\title{
CURSO DE EXTENSÃO EM EDUCAÇÃO DE JOVENS E ADULTOS: DIÁLOGOS ENTRE JUVẺNTUDE, UNIVERSIDADE E A ESCOLA
}

\section{YOUTH AND ADULT EDUCATION EXTENSION COURSE: DIALOGUES BETWEEN YOUTH, UNIVERSITY AND SCHOOL}

Resumo: Este artigo é um relato da experiência do curso de extensão "Educação de Jovens e Adultos (EJA) para a Juventude", realizado na modalidade semipresencial, voltado a professores da educação básica que atuavam no programa Pro Jovem Urbano em vários estados do país. O objetivo principal é refletir sobre um momento das políticas universitárias no qual as diretrizes da extensão universitária caminharam próximas às políticas públicas de inclusão da juventude, através de um maior diálogo com os próprios jovens. Destaca a contribuição do campo extensionista na formação de professores, principalmente por meio das metodologias de diálogo. Reflete sobre os desafios de se fazer extensão a distância, ao lado da importância de mediação pelos próprios jovens, estudantes e ativistas sociais, em um processo de formação educacional intergeracional. Aponta os impactos negativos que a descontinuidade das políticas de formação de professores gera em termos da efetividade dos processos de inclusão.

Palavras chave: Juventude; Extensão universitária; Formação de professores; Educação básica.

\begin{abstract}
This paper reports on the experience of the extension course "Youth and Adult Education (EJA) for Youth", conducted in the blended mode, aimed at teachers of basic education who worked in the Urban ProJovem program in several states of the country. The main objective is to reflect on a moment of university policies in which the university extension guidelines have moved closer to the public policies of inclusion of the youth, through a greater dialogue with the youth. It emphasizes the contribution of the extension field to teachers' initial education, mainly through dialogue methodologies. It reflects on the challenges of developing distance extension projects, along with the importance of mediation by the young people themselves, undergraduate students and social activists, in a process of intergenerational educational qualification. It points out the negative impacts that the discontinuation of teacher education policies generates in terms of the effectiveness of inclusion processes.
\end{abstract}

Keywords: Youth; University Extension; Teacher qualification; Basic education. 


\section{Introdução}

O curso de extensão "Educação de Jovens e Adultos (EJA) para a Juventude", formulado pela Universidade Federal do Estado do Rio de Janeiro (UNIRIO), no âmbito da Rede Nacional de Formação de Profissionais da Educação (RENAFOR), nos anos de 2014 e 2015, esteve direcionado a professores da educação básica vinculados ao Programa Nacional de Inclusão de Jovens (ProJovem Urbano), da Secretaria de Educação Continuada, Alfabetização, Diversidade e Inclusão (SECADI), do Ministério da Educação (MEC) e fez parte de um conjunto de ações de extensão que buscavam se articular com a política nacional de juventude em curso naquele período.

Diante disso, o presente artigo situa a experiência deste curso dentro do ciclo de políticas públicas de juventude ocorrido no Brasil entre 2005 e 2015, período no qual a extensão universitária buscou ampliar seu espectro de parcerias governamentais e participou ativamente da construção de metodologias de diálogo, por meio da participação em programas nacionais que atuaram em sintonia com políticas públicas de inclusão, voltadas principalmente para jovens em situação de vulnerabilidade social. Nesse período, são inúmeras as experiências que a extensão universitária desenvolveu junto aos mais diversos sujeitos jovens: de periferias, quilombolas, ribeirinhos, em privação de liberdade, em situação de rua, refugiados etc.

O objetivo principal é refletir sobre um momento no qual as diretrizes da extensão universitária caminharam próximas às políticas públicas de inclusão, destacando a contribuição do campo extensionista no desenvolvimento de metodologias de diálogo e mediação social. Como objetivos específicos, refletir sobre o potencial do processo de troca de experiências entre docentes universitários e docentes da educação básica, mediado por jovens universitários e por ativistas sociais, como uma ferramenta útil para o aprimoramento das práticas docentes e das pesquisas sobre juventude. E, finalmente, apontar os impasses que os projetos de juventude e de formação de professores enfrentam na atual conjuntura do país.

Vale destacar que este curso de extensão se desenvolveu em um momento no qual uma nova geração de programas governamentais buscava incorporar as demandas dos próprios jovens no debate político, no sentido de trazer tais sujeitos à condição de interlocutores nas decisões que lhes dizem respeito, de modo a romper com a invisibilidade a que vêm sendo historicamente submetidos. Nesse período, a extensão universitária vinha buscando construir uma maior aproximação com políticas públicas de inclusão, provindas principalmente do governo federal, visando, assim, obter ganhos de escala nas ações, o que ocorreu, efetivamente, com a materialização de alguns programas de caráter nacional.

Do mesmo modo, é importante marcar os desafios de se fazer extensão a distância, pois o curso utilizou como metodologia de trabalho uma plataforma virtual, cuja mediação era feita por jovens universitários, somada a encontros presenciais com jovens ativistas de diferentes movimentos sociais. Tal proposta visava colocar em diálogo atores vinculados a diversas políticas públicas de juventude em andamento no período. Assim, parte-se de questões colocadas no processo de desenvolvimento dessa ação extensionista para pensar os desafios que enfrentam as políticas inclusivas, tanto no que se refere à construção de metodologias de diálogo, que funcionem em larga escala, quanto em relação às descontinuidades dessas iniciativas em função da agenda política nacional, o que compromete a efetividade do processo inclusivo. No caso da formação de professores, a recorrência de tais descontinuidades tem sido objeto de reflexão e, portanto, a construção de uma política de formação continuada está entre as principais demandas dos profissionais da Educação Básica (GATTI, 2013).

No que diz respeito à universidade, o diálogo com os profissionais da escola pública e com os jovens se mostra essencial na produção de uma reflexão comprometida com as práticas inclusivas, que respeite e valorize a fala tanto dos professores quanto dos próprios jovens que enfrentam situações de vulnerabilidade. Este aprendizado que reafirma a importância do diálogo e da participação de todos os sujeitos envolvidos integra um dos ganhos mais importantes desse ciclo de políticas de juventude. Nesse sentido, pode-se afirmar que é, também, uma conquista do campo extensionista, que sempre defendeu o diálogo extramuros como essencial na construção de uma universidade cada vez mais inclusiva e democrática.

\section{Os ciclos de políticas públicas de juventude no Brasil}

No Brasil, o período democrático recente teve início em 1988, ano da promulgação da primeira Constituição Federal após a ditadura - a Constituição Cidadã - e os últimos trinta anos foram marcados por um processo crescente de conquistas de direitos, especialmente para a juventude. Ao final da década de 1980, o país já vinha conseguindo equacionar os graves problemas da infância, com uma redução expressiva da mortalidade infantil devido a um esforço governamental, apoiado por organismos internacionais e movimentos sociais, com forte influência da Igreja Católica, principalmente da Pastoral da Criança (NEUMANN, 2006).

Um marco legal que sintetiza as conquistas sociais do período foi a aprovação do Estatuto da Criança e do Adolescente (ECA), em 1990, que garantiu direitos e elencou os deveres do Estado no amparo a tais sujeitos. O ECA representou um grande avanço para a juventude ao ampliar a cobertura do 
Estado aos jovens até 18 anos (Art. $2^{\circ}$ ) e, excepcionalmente, às pessoas entre 18 e 21 anos (Art. $2^{\circ}$, parágrafo único) (BRASIL, 1990). A relevância do ECA se relaciona, também, ao fato de apontar uma nova concepção de sujeito social, não mais como um mero "beneficiário" das políticas governamentais, mas sim pensado como um "sujeito de direitos". ${ }^{1}$

Na década de 1990, o inchaço das metrópoles, com a expansão da pobreza pelas periferias e as mudanças no comércio internacional de drogas e de armas transformaram as cidades brasileiras em locais de risco para os jovens, principais vítimas de morte violenta que atinge, especialmente, homens, pobres, negros e moradores de favelas e de áreas mais pobres das cidades. Assim, a concepção do jovem pobre como potencialmente criminoso levou a intervenções violentas do Estado, principalmente por parte das polícias militares, a ponto de várias entidades de defesa de direitos humanos alertarem que há um genocídio da juventude negra no país, transformando as periferias em zonas de alta vulnerabilidade (WAISELFISZ, 1998). Em função disso, esse primeiro ciclo de políticas públicas associava, frequentemente, juventude à violência, gerando representações politicamente conservadoras sobre os jovens, ainda que encobertas pela retórica do "protagonismo juvenil". Tais perspectivas se traduziram em projetos voltados para a tutela dos jovens, sobretudo para a administração de seu tempo livre, associando tempo ocioso à criminalidade.

Como afirma Rua (1998), uma das principais marcas das políticas públicas para a juventude dessa década foi a sua extrema fragmentação, isto é, ações de saúde que não interagiam com as de educação que, por sua vez, não dialogavam com iniciativas voltadas para o trabalho e assim por diante. Além disso, sofriam de grande descontinuidade, levando a um frequente início, abandono e reinício das ações, o que gerava descrença por parte do público-alvo, desestimulando a sua participação.

Durante os governos do Presidente Fernando Henrique Cardoso (1995-1998 e 1999-2002), houve uma tentativa de maior articulação das políticas sociais por meio da criação do programa "Comunidade Solidária", coordenado pela Primeira-dama, a importante antropóloga Ruth Cardoso, que gerou experiências educacionais muito relevantes, principalmente o projeto "Alfabetização Solidária", envolvendo parcerias com Instituições de Ensino Superior (IES), iniciativa privada, pessoas físicas e governos municipais, estaduais e federal. As críticas de parte da universidade se voltavam principalmente para o pouco diálogo que havia com a longa experiência de intervenção em territórios vulneráveis acumulada pela extensão universitária, tentando enquadrar as ações extensionistas no escopo e na filosofia do programa, o que nem sempre era possível ou desejável.

A despeito de boas iniciativas, a maior parte dos projetos continuava a pensar os jovens como "beneficiários" das políticas, porém raramente eles eram ouvidos nos processos de formulação, implementação e avaliação (DRAIBE, 2003). Isso conduzia a problemas graves em tais ações, pois os jovens pensados nos gabinetes não eram os mesmos do mundo real. Estes sim, portadores de demandas e anseios que, muitas vezes, não eram contemplados por essas iniciativas (RUA, 1998, p.,:741).

O segundo ciclo de políticas públicas de juventude teve como marco inicial o ano de 2004, com a criação do Comitê do grupo interministerial coordenado pela Secretária-geral da Presidência da República e composto por 19 ministérios -, que levantou os principais programas federais para esse segmento populacional e realizou um diagnóstico da situação dos jovens brasileiros (ABRAMO; BRANCO, 2005). A conclusão desse trabalho resultou na promulgação da Lei 11.129, de 30 de junho de 2005, que criou a Secretaria Nacional de Juventude (SNJ), o Conselho Nacional de Juventude (Conjuve) e diversos programas e políticas públicas voltados para os jovens em situação de maior vulnerabilidade social, sendo o principal destes o ProJovem Urbano. Ao contrário do ciclo anterior, no qual há uma retração da presença do Estado, a principal característica do ciclo de políticas iniciado com os governos do Presidente Luiz Inácio Lula da Silva (2003-2006 e 2007-2010) se refere ao fato de que o Estado brasileiro assume, fortemente, seu papel de indutor de políticas públicas de juventude, resultando na criação de um campo que reunia entidades da sociedade civil e do governo.

Porém, a principal transformação que ocorreu nesse período foi uma mudança significativa na política de participação dos jovens nos processos de formulação, implementação e avaliação das políticas a eles destinadas. Nesse sentido, é importante destacar que esse segundo ciclo comportou três Conferências Nacionais de Políticas Públicas de Juventude (CNPPJ), realizadas em 2008, 2011 e 2015, que foram espaços de participação de distintos coletivos juvenis, avaliando e propondo a ampliação de seus direitos, tendo o Conjuve à frente do processo de mobilização nacional, que se dava pela realização de conferências municipais, estaduais, virtuais e específicas (jovens Povos e Comunidades Tradicionais, quilombolas, de terreiro, ribeirinhos etc.), que mobilizavam milhares de jovens e coletivos para a Conferência Nacional, reunindo em Brasília, a cada edição, cerca de 3 mil jovens de todo o país.

\section{Diretrizes da extensão universitária}

A partir dessas mudanças nos rumos das políticas do Estado brasileiro, as universidades públicas se engajaram ativamente em programas nacionais voltados para a diversidade de jovens que chegavam, cada vez em maior número, às universidades e Institutos Federais criados no período. Um primeiro grande esforço feito pela extensão 
universitária foi o desenvolvimento de plataformas virtuais de registro das atividades que fossem mais modernas e intercambiáveis, resultando na construção de dois sistemas de informações, o SIEX e a Plataforma SigProj. Um segundo movimento, que tem relação direta com este relato de experiência, foi a articulação com ministérios e organismos envolvidos nessas políticas de inclusão.

A manutenção de uma rede de formação como a RENAFOR, que aproxima a universidade da escola pública, é o resultado de uma articulação política de diversos atores e instituições em um momento específico do país, caracterizando um ciclo de políticas públicas de juventude entre 2005 e 2015 . O curso de extensão "Educação de Jovens e Adultos (EJA) para a Juventude" deve ser compreendido como um produto desse período e, portanto, enfrenta um processo de descontinuidade à medida que esse ciclo se encerra. Logo, é importante refletir sobre a relação dessas experiências específicas com as diretrizes das políticas nacionais, pois este é um campo de articulação política no qual o Fórum Nacional de Pró-Reitores de Extensão das Instituições Públicas de Educação Superior Brasileiras - FORPROEX tem investido muitos esforços.

O XXXIII Encontro Nacional do Fórum Nacional de Pró-Reitores de Extensão das Instituições Públicas de Educação Superior Brasileiras FORPROEX, ocorrido no Rio de Janeiro, em maio de 2013, teve como tema "Políticas Afirmativas e Juventude" e constituiu um movimento importante de articulação da comunidade acadêmica com outras forças sociais, pois apontava os desafios colocados para a universidade pública e, particularmente, para a extensão universitária, pelos processos sociais e políticos decorrentes do avanço da democracia no país, que, nos últimos anos, se traduziram em políticas públicas de acesso e permanência de jovens de origem popular no ensino superior, transformando o perfil dos estudantes universitários brasileiros. Nesse processo recente de democratização da universidade, a extensão universitária tem funcionado como uma "porta de entrada" de boa parte desses jovens na vida acadêmica, pois o campo extensionista constituiu-se, historicamente, a partir do reconhecimento e da valorização de vivências e saberes dos grupos populares e, portanto, tem lidado com essa maior diversidade estudantil como uma dimensão importante da universidade plural, inclusiva e com relevância social que se almeja construir no século XXI.

Assim, o documento final do XXXIII FORPROEX, intitulado "Carta do Rio", de maio de 2013, caminhava nessa direção ao afirmar a importância da agenda da juventude:

Reunidos no Rio de Janeiro, entre os dias 06 e 08 de maio de 2013, durante o XXXIII Encontro Nacional do FORPROEX, os Pró-Reitores de Extensão das Instituições Públicas de Educação Superior Brasileiras debateram os desafios e as perspectivas da extensão universitária frente aos desafios contemporâneos e à superação das desigualdades, com foco especial para as políticas de juventude, educação superior e extensão universitária (FORPROEX, 2013).

O $5^{\circ}$ ponto da agenda institucional de compromissos do FORPROEX reafirma a importância do tema:

5. apoio ao esforço da Secretaria Nacional da Juventude em construir uma agenda de compromissos interministerial para consolidação das políticas para a juventude (FORPROEX, 2013).

A "Carta do Rio" sintetizava um esforço de articulação interinstitucional do FORPROEX que já vinha ocorrendo nos últimos anos, mobilizando as PróReitorias de Extensão a buscar maior participação em projetos voltados para a juventude. Nesse ciclo, foram criados importantes programas de extensão com uma interface com políticas públicas de garantia do direito à educação de jovens em situação de vulnerabilidade social. A existência de um programa nacional tende a potencializar inúmeras iniciativas, na forma de projetos e programas desenvolvidos por cada universidade, que contemplavam também esses sujeitos localmente. Nesse sentido, a extensão universitária buscava ser um suporte importante na trajetória desses jovens na universidade, garantindo sua permanência mais qualificada, por estar baseada em participação em projetos de pesquisa e intervenção nos territórios.

Esse ciclo de políticas começa a declinar politicamente em 2013. Parafraseando o livro do jornalista Zuenir Ventura, "1968: O Ano Que Não Terminou” (VENTURA, 1988), 2013 é uma espécie de "ano que não terminou", uma vez que as consequências políticas das "Jornadas de Junho", ocorridas naquele ano, ainda estão em curso. As "Jornadas" tiveram início com as manifestações do Movimento Passe Livre contra o aumento de tarifas de transporte público em São Paulo, mas a violenta repressão policial gerou uma revolta difusa que assumiu ares de insurreição popular, levando milhares de jovens a ocupar as ruas de todo o país. Embora comporte uma vitória aparente dos jovens, já que o Estatuto da Juventude (EJ) foi promulgado imediatamente após, em 5 de agosto de 2013, como uma resposta do governo às manifestações, as "Jornadas" marcam, também, o início do uso midiático da juventude em um ensaio para o golpe parlamentar, que viria a cortar gastos e esvaziar programas, levando à regressão da maioria dos projetos da nascente Política Nacional de Juventude.

Esse ciclo se encerra no segundo governo da Presidenta Dilma Rousseff (2011-2014 e 2015-2016), com a ruptura institucional decorrente do golpe parlamentar-jurídico-midiático ocorrido no país em 2016, que busca encerrar o período de redemocratização iniciado em 1988 e implementar um projeto ultraliberal, que alguns autores têm chamado de "regime constitucional não democrático" 
SANTOS, 2017) ou "Estado Pós-democrático" ( CASARA, 2018). A lógica do Estado se torna contrária à garantia de direitos sociais e voltada unicamente para o atendimento das demandas do "mercado". Essa configuração atinge, particularmente, os projetos educacionais para jovens, que são vistos nesse modelo como mão de obra farta e barata para alimentar a acumulação predatória do capitalismo contemporâneo, que - sob o comando do grande capital financeiro internacional - vem desestabilizando regimes democráticos em toda a América Latina.

\section{O Curso de "Educação de Jovens e Adultos (EJA) para a Juventude"}

A criação de uma Rede Nacional de Formação de Profissionais da Educação (RENAFOR) também é uma conquista recente, já que foi instituída pela Resolução $\mathrm{N}^{\circ} 24$ do Fundo Nacional de Desenvolvimento da Educação (FNDE), de 16 de agosto de 2010 (BRASIL, 2010), que estabeleceu as bases para uma política nacional de formação de professores da educação básica. O Curso "Educação de Jovens e Adultos (EJA) para a Juventude" integrava a oferta a cargo da SECADI/MEC, que abrigava cursos de formação continuada que visavam formar professores para o desenvolvimento de práticas inclusivas, capazes de valorizar a diversidade humana, com suas diferenças culturais, geracionais, étnicas, raciais, de gênero, físicas, sensoriais, intelectuais, linguísticas, dentre outras, bem como por meio da valorização dos ecossistemas, com respeito ao meio ambiente. Portanto, parte-se da premissa de que a formação continuada é uma ferramenta eficaz para aprimorar processos inclusivos, à medida que fornece aos professores referenciais mais atualizados sobre as múltiplas desigualdades que atingem os sujeitos de sua ação, os estudantes. Logo, o processo inclusivo não é somente um ato de vontade política, mas depende de técnicas capazes de aprimorar a experiência prática já acumulada pelos docentes.

Em 2005, o ProJovem surgiu como o principal programa da recém-instituída Política Nacional de Juventude, que criou a Secretaria Nacional de Juventude (SNJ), vinculada à Secretaria Geral da Presidência da República (SGPR) e instituiu, também, o Conselho Nacional de Juventude (Conjuve), composto por jovens ativistas sociais. O ProJovem foi rebatizado em 2007 como ProJovem Urbano, mas ainda era pensado como uma "ação emergencial", destinada ao atendimento de jovens entre 18 e 29 anos que, apesar de alfabetizados, não concluíram o ensino fundamental. Em 2012, migrou para o MEC, integrando a oferta de Educação de Jovens e Adultos.

O programa foi concebido com a finalidade de promover a reinserção desses jovens na escola e sua inserção no mundo do trabalho, mediante a conclusão do segmento fundamental da educação básica, a qualificação profissional e o desenvolvimento de experiências de participação cidadã. Tinha como fundamentos: (a) o reconhecimento do jovem como sujeito de direitos, (b) o respeito à singularidade da condição juvenil, suas necessidades e desejos, frente à sua condição socioeconômica e cultural, e (c) a viabilização de sua participação ativa no processo de aprendizagem. Conforme seu Projeto Políticopedagógico, o programa buscava superar os grandes hiatos existentes entre escola e vida, entre aprendizado teórico e prático, entre escola e mundo do trabalho, entre a preparação do cidadão para $\mathrm{o}$ futuro $\mathrm{e}$ a participação do jovem cidadão no presente. Dentre os anseios dos docentes do ProJovem Urbano, a formação continuada sempre apareceu como uma demanda importante, frente aos enormes desafios colocados pela proposta, que combinava aceleração da aprendizagem, formação para o trabalho e participação cidadã.

Em sua operacionalização, o ProJovem Urbano se organizava por turmas que, reunidas, formavam Núcleos. Cada Núcleo devia contar com cinco professores habilitados nas diferentes áreas do ensino fundamental (Língua Portuguesa, Matemática, Ciências Sociais, Ciências da Natureza e Língua Estrangeira). Cada Núcleo deveria dispor, também, de docentes responsáveis pela qualificação para o trabalho nas áreas escolhidas para cada turma, ou contar com organizações parceiras que dispusessem de profissionais e equipamentos. Além desses profissionais, contava com Assistentes Sociais que se incumbiam das discussões que embasavam a dimensão de Formação Cidadã. Esperava-se que todos os professores pudessem atuar como professoresorientadores - um por turma - e como professoresespecialistas, em horários previamente estabelecidos. Para cada turma, deveria haver um professororientador incumbido de sua regência, de modo que pudesse estabelecer os vínculos necessários para uma efetiva orientação educacional de cada aluno individualmente e do grupo (BRASIL, 2008).

Dar conta dessa proposta pedagógica é um desafio que mobilizava, sobremaneira, a coordenação nacional do Programa, seus gestores, equipes das coordenações estaduais e municipais e, de maneira muito especial, os seus professores. Isso porque aos professores cabia dar vida e tornar realidade o conjunto de proposições formuladas neste singular projeto político-pedagógico. Eram eles que estavam mais perto dos jovens, ouvindo cotidianamente suas demandas, necessidades, desejos e críticas. Por isto mesmo, passados alguns anos da implementação do Programa, a formação continuada tornou-se imperativa, pois tais docentes lidavam com uma grande carga de trabalho em um modelo pedagógico inovador, requerendo um diálogo com outros atores do campo educacional como forma de ajustar instrumentos de avaliação e pensar em atividades mobilizadoras de um público que já vinha de sucessivos fracassos em sua trajetória educacional, cabendo ao Programa a responsabilidade de garantir a esse sujeito algum grau de autonomia e projeto de futuro (ANDRADE; ESTEVES; CASTRO, 2009). 
Em pesquisa realizada pela SECADI em 2010, cerca de três quartos dos docentes $(76,5 \%)$ declararam que a formação continuada oferecida atende às suas expectativas, tanto por apresentar debates contemporâneos do campo educacional quanto por permitir a troca de experiências com docentes que experimentavam desafios semelhantes. No entanto, essa preponderância não deve obscurecer outro dado preocupante, indicando que quase um quarto deles assinala que essa formação deixa a desejar, principalmente por ser demasiadamente teórica e não dialogar com as unidades formativas usadas em sala (SECADI/MEC, 2010).

Tendo como base tais demandas, a UNIRIO formulou o curso de extensão "Educação de Jovens e Adultos (EJA) para a Juventude", partindo da premissa de que as últimas décadas trouxeram mudanças profundas no cenário mundial, com o processo de globalização dos mercados, de desterritorialização dos processos produtivos e de flexibilização das relações de trabalho, gerando transformações econômicas, tecnológicas e culturais que afetaram diretamente a juventude. De um lado, acentuaram-se os traços perversos de uma sociedade centrada no consumo voraz de mercadorias como forma de distinção, reforçando $\mathrm{o}$ individualismo em detrimento de processos coletivos. No entanto, em direção contrária, nunca foi tão fácil se comunicar, acionar parcerias e atuar em rede, experiência que os jovens dominam com habilidade, o que é uma vantagem da primeira geração nascida em um mundo inteiramente digital.

Desafiado por essa nova configuração do mundo e pelo imperativo de formar docentes dispersos por vários estados brasileiros, o Projeto Políticopedagógico do curso, formulado pela universidade, baseou-se em uma metodologia semipresencial, associando o modelo de educação presencial aos recursos da educação a distância. Assim, cada curso teve 2 (dois) encontros presenciais distribuídos no decorrer das atividades, mas se desenvolveu, na maior parte do tempo, no âmbito do ambiente virtual de aprendizagem (AVA), utilizando a plataforma MOODLE, que dispõe de ferramentas de comunicação e de recursos para trabalhar seu conteúdo programático em texto, imagem, vídeo e áudio. Este trabalho contava com a participação de jovens mestrandos e doutorandos em Educação atuando como tutores. Cada tutor acompanhava 25 cursistas e era responsável por promover debates virtuais - usando um chat, isto é, uma plataforma virtual de bate-papo - que serviam para se discutir cada nova aula disponibilizada.

A estrutura curricular dos cursos organizava-se como uma rede resultante do cruzamento de eixos estruturantes (juventude e cultura, cidade, trabalho, comunicação, tecnologia, cidadania) com os conteúdos curriculares selecionados (Ciências Humanas, Língua Portuguesa, Inglês, Matemática, Ciências da Natureza, Qualificação Profisssional, Participação Cidadã). Como pano de fundo para essas atividades, apresentavam-se pesquisas atuais sobre juventude.
Assim, visava: 1) Formar professores do ProJovem Urbano, em nível nacional, no que se refere à análise sobre a diversidade da juventude brasileira, suas necessidades, demandas, desafios e desejos; 2) Fomentar a reflexão sobre a construção de uma educação adequada à vida dos jovens atendidos no programa; 3) Contribuir para a qualificação tanto de profissionais que atuam no ProJovem Urbano quanto de pesquisadores universitários, por meio da troca de experiências e reflexões mais integradas sobre a juventude contemporânea.

Além de envolver somente estudantes da pósgraduação, outro diferencial do curso foi o investimento no uso das tecnologias de informação e comunicação (TIC), por meio de uma plataforma MOODLE $^{2}$, que funcionava como um ambiente virtual de aprendizagem (AVA), contendo aulas, filmes, grupos de discussão e espaço para apresentação de trabalhos parciais e finais. Em 2014, o primeiro curso de extensão formou 220 docentes do ProJovem Urbano, com uma carga horária total de 120 horas, sendo 88 horas em ambiente virtual de aprendizagem (AVA), com acompanhamento permanente de 1 tutor para cada 25 cursistas. Em 2015, o segundo curso formou 150 professores do programa, com carga horária de 180 horas, sendo 120 horas em AVA. A maior carga horária permitiu adensar a discussão e ampliar as aulas, que seguiram os 11 eixos do Estatuto da Juventude. Embora continuasse sendo certificado como uma ação de extensão universitária, o segundo curso foi em nível de Aperfeiçoamento. Ambos tiveram dois encontros presenciais: em 2014, no Rio de Janeiro e Brasília; em 2015, em Natal e no Rio de Janeiro. Nesses encontros, havia a participação de jovens ativistas de diferentes movimentos sociais, que narravam as suas atuações como militantes e refletiam sobre os desafios enfrentados em suas trajetórias educacionais, contando, ainda, com a participação de pesquisadores do campo da juventude

Um dos grandes desafios de se trabalhar com a juventude diz respeito à necessidade de os próprios educadores compreenderem os sentidos do que é ser jovem em um tempo marcado por intensas transformações e, assim, saberem lidar com essas novas formas de ser e estar no mundo que os jovens contemporâneos reivindicam. Trata-se de compreender que "toda experiência geracional é inédita" (NOVAES, 2006, p.126), logo, aprender a trabalhar com a juventude é uma tarefa urgente para todos os educadores, pois nos próximos anos o Brasil deverá investir maciçamente em seus jovens se quiser aproveitar os últimos momentos do chamado "bônus de juventude", já que brevemente começará a experimentar um processo de envelhecimento populacional.

Porém, hoje, um quarto dos brasileiros ainda é jovem, $24,6 \%$ da população em 2017, e temos, portanto, mais de 51 milhões de indivíduos entre $15 \mathrm{e}$ 29 anos de idade que, em sua enorme diversidade, compõem a juventude brasileira. É sobre os desafios que a juventude representa para a construção de um 
projeto de Nação, este "inédito viável", para usar a expressão de Paulo Freire, que este texto busca refletir ao narrar a experiência desse curso de extensão voltado para a formação de professores do ProJovem Urbano.

Quadro 1: Estrutura curricular do Curso de Extensão de 2014

• Unidade Formativa I - Juventude e Cultura
Ementa: Ser jovem hoje; A cultura da comunidade em que os alunos vivem (saberes, fazeres,
crenças e expressões artísticas); preconceitos e discriminação; qualidade de vida; os hábitos
culturais da comunidade e o respeito à natureza.
• Unidade Formativa II - Juventude e Cidade
Ementa: Viver na cidade. O bairro, território. A violência urbana e o dia-a-dia dos jovens. Educação,
trabalho e lazer ao alcance de todos. Saneamento básico é importante.
- Unidade Formativa III - Juventude e Trabalho
Ementa: Ser jovem: aprendendo e trabalhando. Juventude e consumo. A violência e a situação de
trabalho. Direitos do trabalhador. Trabalho e meio ambiente.
- Unidade Formativa IV - Juventude e Comunicação
Ementa: Comunicação: importância para a vida e trabalho. Meios de comunicação: integração ou
exclusão? Sexualidade e responsabilidade. Acesso dos jovens aos meios de comunicação. Meio
ambiente e comunicação no mundo globalizado
- Unidade Formativa V - Juventude e Tecnologia
- Unidade Formativa VI - Juventude e Cidadania
formas de exclusão. Tecnologia e o meio ambiente.
Ementa: o ProJovem Urbano e a cidadania. Morar na cidade e no campo: semelhanças e diferenças.
Deslocamentos e migrações. Responsabilidade pelo meio ambiente e juventude.

Fonte: Projeto Político-pedagógico Curso Educação de Jovens e Adultos para a Juventude, RENAFOR, 2014

Quadro 2: Estrutura curricular do Curso de Extensão/Aperfeiçoamento

O Estatuto da Juventude (EJ)
- Unidade Formativa I - Juventude e Cultura
Ementa: Diversidade e Igualdade (eixo IV do EJ); Cultura (eixo VI do EJ)
• Unidade Formativa II - Juventude e Cidade
Ementa: Território e Mobilidade (eixo IX do EJ); Segurança Pública e Acesso à Justiça (eixo XI)
- Unidade Formativa III - Juventude e Trabalho
Ementa: Profissionalização, Trabalho e Renda (eixo III do EJ); Educação (eixo II do EJ)
- Unidade Formativa IV - Juventude e Comunicação
Ementa: Comunicação e Liberdade de Expressão (eixo VII do EJ); Sustentabilidade e Meio Ambiente
(eixo X do EJ)
- Unidade Formativa V - Juventude e Tecnologia
Ementa: Comunicação e Liberdade de Expressão (eixo VII do EJ);
- Unidade Formativa VI - Juventude e Cidadania
Ementa: Cidadania, Participação Social e Politica e Representação Juvenil (eixo I do EJ); Desporto e
Lazer (eixo VIII do EJ)

Fonte: Projeto Político-pedagógico Curso Educação de Jovens e Adultos para a Juventude, RENAFOR, 2015

Conforme se vê nos Quadros 1 e 2, tal desenho curricular visava promover um diálogo que permitisse tanto conhecer desses docentes as suas experiências com os jovens do programa quanto apresentar a eles pesquisas e reflexões sobre a situação, as demandas e os anseios da juventude contemporânea, especialmente dos jovens brasileiros. $\mathrm{O}$ processo de ensino/aprendizagem era mediado por estudantes universitários, mestrandos e doutorandos em Educação, que atuavam como tutores nas atividades da plataforma usada para a educação a distância. Nos eventos presenciais, contava-se, ainda, com a participação de jovens ativistas narrando suas experiências como membros de diversos coletivos e movimentos sociais de juventude, bem como de pesquisadores do campo de estudos da juventude.

Nenhum processo de inclusão ocorre sem desafios. No que se refere à relação juventude/educação, esses desafios se colocam inicialmente para os professores da educação básica, sobretudo para os do ensino fundamental, onde está a maior parcela desses jovens, muitos dos quais sequer chegarão ao ensino médio e, menos ainda, à universidade. Portanto, foi muito importante ouvir dos professores da educação básica as suas experiências de trabalho cotidiano com jovens da escola pública e, particularmente, dos matriculados no ProJovem Urbano, em sua maioria jovens de origem popular. Isso porque predomina no imaginário social a representação da escola pública como um espaço caracterizado por múltiplas precariedades, o que acaba por estigmatizar, também, os seus estudantes. De fato, os baixos salários dos professores, a sobrecarga de trabalho, as instalações físicas precárias ou degradadas e o avanço da violência no cotidiano escolar têm afetado muitas escolas públicas, mas esse quadro - que é dramático e real, principalmente nos grandes centros urbanos - não dá conta do importante papel que a escola pública continua desempenhando na vida dos jovens brasileiros, seja como espaço de socialização em territórios onde o poder público pouco chega, seja como instituição fundamental para a mobilidade social de jovens das classes populares.

\section{Descobertas, ganhos e desafios}

O ProJovem Urbano se voltou para jovens entre 18 e 29 anos, que já haviam abandonado a escola algumas vezes e muitos deles sequer se pensavam mais como sendo jovens e, portanto, como tendo direitos específicos da juventude. Trabalhar com um alunado com esse perfil é, sem dúvida, um grande desafio. Portanto, o principal objetivo dos cursos ofertados de formação para os docentes do Programa foi, justamente, pensar a condição juvenil contemporânea e debater com eles sobre a necessidade de se compreender o que é ser jovem no tempo presente, evitando-se, assim, comparações simplistas entre gerações, expressas em frases muito comuns nos discursos docentes, tais como: "no meu tempo os jovens eram mais politizados". Desconstruir estigmas não é tarefa simples, ainda mais quando se está lidando com profissionais que já atuam como docentes há alguns anos e, portanto, tendem a naturalizar discursos do cotidiano. Por isso, era necessário causar um certo estranhamento e, nesse sentido, as pesquisas, os grupos de discussão com os jovens da pós-graduação e a presença de jovens ativistas tinham essa finalidade. Desconstruir estereótipos e aproximar gerações.

Ao se concluir a segunda edição do curso, ficou claro o bom resultado que o uso de um Ambiente Virtual de Aprendizagem (AVA) pode proporcionar para projetos nacionais, pois embora já sejam mais 
presentes nas atividades de ensino e pesquisa, ações a distância ainda não ocorrem com frequência na extensão. Como o projeto reunia professores da rede básica de diversas regiões do país, foi possível uma troca de conhecimentos e experiências que realçava as distinções territoriais. Nesse sentido, foi muito enriquecedor expor afinidades e diferenças, partindo do debate intergeracional até abarcar as diferenças regionais do país.

O uso do AVA foi uma maneira de aproximar esses docentes da experiência cotidiana de seus estudantes, jovens de uma geração que é "nativa digital", isto é, nascida em um mundo já digital, onde as tecnologias de informação têm papel preponderante. Logo, construir um processo de formação por meio da integração de ações formativas presenciais e não presenciais ampliou os sentidos de todos os participantes sobre essa nova dimensão virtual da vida social, promovendo um tipo de formação que oferecia aos professores-cursistas elementos teóricos e técnicos para o desenvolvimento de novas práticas docentes em sintonia com o universo de referências de seus estudantes. Mais ainda, o uso do AVA dava mais flexibilidade de os professores combinarem sua intensa carga horária de trabalho na escola com um curso de formação que durava meses, pois o material estava disponível para ser acessado a qualquer momento e havia sempre a preocupação e o cuidado em produzir um material didático dinâmico, combinando aulas, filmes, depoimentos de jovens etc., o que se acredita ter diminuído a evasão durante o curso.

Houve uma interação muito forte entre os cursistas, que eram docentes do ProJovem Urbano, na faixa etária entre 40 e 50 anos, e os tutores, que eram estudantes de Mestrado e Doutorado em Educação, na faixa etária entre 20 e 30 anos. Essa dinâmica aproximava docentes que já lecionam para jovens, aprendendo e ensinando com jovens pesquisadores que, por sua vez, tinham interesse em políticas educacionais direcionadas à juventude. Os estudantes universitários tinham, assim, a oportunidade de debater os seus temas de pesquisa com docentes que já vivenciavam cotidianamente as questões que eles estavam pesquisando, promovendo um intercâmbio de informações e, mais que isso, de experiências de vida.

Finalmente, foi muito importante conhecer as experiências de jovens ativistas, convidados nos encontros presenciais, pois indicavam a necessidade de se pensar uma agenda para a juventude que dê conta das especificidades das demandas dos jovens de hoje, principalmente a pluralidade de condições juvenis, que colocam desafios distintos de proteção e de promoção de oportunidades de desenvolvimento, sobretudo na condição do jovem pensado como "sujeito de direitos".

Do mesmo modo, essa experiência aponta que a análise do campo educacional não pode se limitar à esfera escolar, existindo um imenso e rico campo da educação não-escolar que deve também ser contemplado pelas políticas públicas, como é o caso de muitos movimentos sociais voltados para a educação e que funcionam, eles próprios, como campos de aprendizagem.

Para os docentes do ProJovem Urbano ficaram mais claros os novos padrões presentes na interação juventude-escola, como, por exemplo, as novas relações entre escolaridade e inserção no mundo do trabalho; articulação com as novas tecnologias e redes sociais que promovem novas maneiras de estar no mundo; novos arranjos familiares; sustentabilidade socioambiental; estabelecimento de direitos humanos; valorização da diversidade e de novas identidades. Eles relatavam que vivenciavam essas experiências com os jovens para os quais lecionavam, mas não conseguiam relacionar as experiências individuais com padrões mais gerais que afetam hoje o conjunto da juventude brasileira.

\section{Conclusões provisórias}

Entre 2005 e 2015, o Brasil experimentou seu maior ciclo de políticas públicas voltadas para a juventude, interrompido em 2016 com a ruptura institucional ocorrida com o impeachment da presidenta Dilma Rousseff. Ruptura é, de fato, a melhor palavra para descrever o término desse ciclo. A descontinuidade tem sido uma marca das políticas públicas brasileiras, mas conceitualmente, e sobretudo na prática, descontinuidade é diferente de ruptura. $\mathrm{Na}$ descontinuidade, muitas ideias e experiências de gestões anteriores são transmitidas através, principalmente, dos técnicos governamentais, que atravessam diferentes governos, mas também por meio dos balanços feitos sobre tais ações, projetos e programas. Há uma troca de experiências muito relevante e produtiva, em que ideias, práticas e políticas são reavaliadas e novamente implementadas, gerando uma transmissão de conhecimentos mais contínua. Na ruptura, ao contrário, o que há é uma mudança das políticas em direção oposta à que se caminhava até então. Vive-se um momento de ruptura, no qual um conjunto de projetos, programas e políticas estanca e recua a passos largos.

Esta situação não é propriamente nova, mas a atual ruptura é distinta da tradicional descontinuidade, principalmente por querer cessar com qualquer obrigação do Estado na oferta de cobertura social básica à população. A PEC $55^{3}$, que congela gastos sociais por 20 anos, visa extinguir o papel das políticas públicas, repassando o máximo de atribuições para agentes do mercado. Como bem definiu a economista Maria da Conceição Tavares, tal proposta para um país com a nossa dimensão e desigualdade "é uma espécie de suicídio programado" (TAVARES, 2018). Mas essa tentativa de extinção das políticas públicas tem grande possibilidade de fracassar, seja por não ser possível cortar tantos gastos imediatamente, seja pela convulsão social que a não-oferta de serviços básicos à população é capaz de gerar. De todo modo, o país vive mudanças 
bruscas nos rumos das políticas sociais, criando uma situação ambígua na qual os programas educacionais para a juventude nem foram extintos, tampouco têm continuidade. Esse processo atingiu não só o ProJovem Urbano, mas boa parte das políticas públicas de juventude que estavam em construção e nas quais a extensão universitária vinha desempenhando um papel relevante. Isso torna mais urgente a necessidade de muitos balanços e avaliações sobre o que houve nos últimos anos em termos de políticas de inclusão voltadas para a juventude e para a formação de professores.

Isso porque, em qualquer área do conhecimento, para se avançar é fundamental sistematizar, analisar e refletir sobre as experiências acumuladas, pois a história, mesmo que recente, é um campo essencial de pesquisa para as Ciências da Sociedade (Sociologia, Antropologia, Ciência Política etc.). Assim, a experiência constitui uma espécie de laboratório, onde se pode observar o que foi feito e aprender com isso. $\mathrm{O}$ sociólogo Émile Durkheim, pioneiro da disciplina no século XIX, chamava atenção para o fato de que a Pedagogia não se constituía propriamente numa ciência, uma vez que seus fundamentos se encontravam em outros campos disciplinares, como Filosofia, História, Sociologia etc., porém todo esforço educacional é, sim, uma ciência da prática. Portanto, a história da Pedagogia pode ser contada através das práticas educativas desenvolvidas em cada período, com seus condicionantes sociais e políticos, matrizes conceituais e, principalmente, pela análise dos sujeitos da educação sobre os quais essas práticas incidiram e afetaram.

No entanto, apesar desse consenso do ponto de vista epistemológico, não há uma prática sistemática de pesquisas voltadas para a avaliação de grandes programas e políticas públicas educacionais no Brasil. Essa lacuna tem a ver tanto com fatores políticos quanto científicos. Do ponto de vista político, se paga o preço de o país ser ainda uma jovem democracia e, portanto, muito sujeito a turbulências nas passagens de governos, o que leva a que experiências anteriores sejam esquecidas e não avaliadas, pois a tendência de todo governo é sempre "começar do zero", fazendo com que a descontinuidade seja a marca mais forte das políticas públicas brasileiras. Do ponto de vista científico, a reflexão sobre as políticas públicas foi, durante muito tempo, uma tarefa restrita ao campo da Ciência Política. No entanto, nos últimos anos, aumentou o interesse pelos debates acerca desse tema, de modo que diferentes áreas de conhecimento se voltassem para as políticas públicas como um campo importante para pesquisar o surgimento de novos sujeitos e temas (NOVAES et al., 2016).

A partir de 2016, o Programa ProJovem Urbano enfrentou muitas dificuldades em abrir novas turmas, mantendo-se em funcionamento os núcleos ainda existentes, em fase de finalização dos 18 meses previstos para a formação desses jovens no ensino fundamental. Por isso, a terceira edição do curso "Educação de Jovens e Adultos (EJA) para a
Juventude" (UNIRIO/SECADI-MEC), prevista para ocorrer em 2016, foi também cancelada com a justificativa de cortes nas verbas governamentais para a educação.

No entanto, um ciclo virtuoso de políticas públicas, como o experimentado nesse período recente, deixa marcas nos sujeitos e nas instituições. $E$ isso não se apaga facilmente, pois se forjaram identidades e se constituíram direitos. As demandas sociais tampouco se extinguem e vão aparecer, de forma mais ou menos organizada, na ação daqueles sujeitos que vivenciaram um processo democrático de maior intensidade. Embora a mudança de mentalidades seja um processo de longa sedimentação, os cursos de formação permanente de docentes, como a experiência aqui descrita, têm um papel fundamental ao colocar os diferentes sujeitos sociais em diálogo.

Paulo Freire, no livro "Pedagogia da Esperança", trabalha com a categoria "inédito viável" (FREIRE, 1992) como algo que nunca foi experimentado, mas que nem por isso é impossível de ser realizado. Quando se pensa na juventude brasileira, com seu peso enorme na definição de um projeto soberano de nação, fica claro que - mais que nunca - é preciso exercitar a capacidade de a sociedade apostar em um projeto novo, que tenha seu foco na expansão de direitos. Para tal, é necessário manter e ampliar um ambiente de diálogo democrático, que é uma missão que a extensão universitária, ao longo de sua história, já demonstrou que sabe promover com qualidade. Certamente, nos tempos que correm no país, esse atributo da extensão universitária pode ser um trunfo importante para que a universidade pública e de qualidade seja, cada vez mais, referenciada socialmente e, assim, possa vir a contribuir no processo de transformação social.

\section{Bibliografia}

\begin{abstract}
ABRAMO, H.W.; BRANCO, P.P.M. (org.). Retratos da Juventude Brasileira. Análises de uma Pesquisa Nacional. São Paulo: Instituto Cidadania/Editora Fundação Perseu Abramo, 2005.
\end{abstract}

ANDRADE, E.R.; ESTEVES, L.C.G.; CASTRO, E. Composição social e percursos escolares dos sujeitos do ProJovem: novos/velhos desafios para o campo da Educacão de Jovens e Adultos. Brasília: Em Aberto, v. 82, p. 73-89, 2009.

BRASIL. Presidência da República. Estatuto da Criança e do Adolescente. Lei n ${ }^{\circ} 8.069$ de 13 de julho de 1990 . Disponível em

$<$ http://www.planalto.gov.br/Ccivil 03/leis/L8069.htm> Acesso em: 31 jan. 2018.

BRASIL. Ministério da Educação. Conselho Nacional de Educação. Parecer CNE/CEB, ${ }^{\circ} 18$ Apreciação do Projeto Pedagógico Integrado e autorização de funcionamento do ProJovem Urbano, homologado em 06 de agosto de 2008. Disponível em <

http://portal.mec.gov.br/index.php?option=com_docman\&vi $\mathrm{ew}=$ download\&alias $=9903$-projovem-urbano-parecer-18$2008 \&$ category_slug $=$ fevereiro-2012-pdf\&Itemid=30192 $>$ Acesso em: 30 jan. 2018. 
BRASIL. Ministério da Educação. Fundo Nacional de Desenvolvimento da Educação. RENAFOR. Resolução $\mathbf{n}^{\mathbf{0}}$ 24, de 16 de agosto de 2010.

BRASIL. Estatuto da Juventude. Lei $\mathrm{N}^{\circ} 12.852$, de $\mathrm{O} 5$ de agosto de 2013. Disponível em

$<$ http://www.planalto.gov.br/ccivil 03/ Ato2011-

2014/2013/Lei/L12852.htm> Acess̄o e⿳亠丷: 30 jan. 2018.

CASARA, Rubens. Estado Pós-Democrático: Neoobscurantismo e Gestão dos Indesejáveis. Rio de Janeiro: Civilização Brasileira, 2018.

DRAIBE, Sônia. A política social no período FHC e o sistema de proteção social. São Paulo: Revista Tempo Social, v.15, n.2, nov. 2003.

FORPROEX. XXXIII Encontro Nacional do Forproex Carta do Rio de Janeiro 14/05/2013. RENEX. Rede

Nacional de Extensão. Disponível em

https://www.ufmg.br/proex/renex/index.php/noticias/67xxxiii-encontro-nacional-do-forproex-carta-do-rio-dejaneiro Acesso em: 31 Jan., 2018.

FREIRE, Paulo. Pedagogia da Esperança. Um Reencontro com a Pedagogia do Oprimido. Rio de Janeiro: Paz e Terra, 1992.

GATTI, Bernadete A. Educação, escola e formação de professores: políticas e impasses. Educar em Revista, Curitiba, Brasil, n. 50, p. 51-67, out./dez. 2013. Editora UFPR.

NEUMANN, Zilda Arns. Conhecimento e solidariedade que geram inclusão social. O caso da Pastoral da Criança. Brasília: Revista Inclusão Social, v.1, n.2, p. 88-91, abr./set. 2006.

NOVAES, Regina. Os jovens de hoje: contextos, diferenças e trajetórias. In: ALMEIDA, M.I.M.; EUGÊNIO, F. Culturas Jovens: Novos Mapas do Afeto. p. 105-120. Rio de Janeiro: Jorge Zahar, 2006.

NOVAES, Regina; VENTURA, Gustavo; RIBEIRO, Eliane; PINHEIRO, Diógenes. Agenda Juventude Brasil. Leituras sobre uma década de mudanças. Rio de Janeiro: Editora UNIRIO, 2016.
RUA, Maria das Graças. As políticas públicas e a juventude dos anos 90. In: CNPD Jovens Acontecendo nas Trilhas das Políticas Públicas. Brasília: CNPD, 1998.

SANTOS, Wanderley Guilherme. A Democracia Impedida. O Brasil no Século XXI. Rio de Janeiro: Editora FGV, 2017.

SECADI/MEC. Educadores do ProJovem Urbano: Opiniões, Avaliações e Expectativas. Relatório de

Acompanhamento. Brasília: SECADI/MEC, 2010.

TAVARES, Maria da Conceição. "PEC 241 é um suicídio programado", diz Maria da Conceição Tavares. Economista diz que medida vai contra preceitos do próprio FMI. Jornal do Brasil, Rio de Janeiro, 2018, disponível em $<$ http://www.jb.com.br/pais/noticias/2016/10/13/pec-241-eum-suicidio-programado-diz-maria-da-conceicao-tavares/> Acesso em: 31 jan. 2018.

VELHO, Gilberto. Projeto e Metamorfose: Antropologia das Sociedades Complexas. 3.ed. Rio de Janeiro: Jorge Zahar Editora, 2003.

VENTURA, Zuenir. 1968: O Ano que Não Terminou. Rio de Janeiro: Nova Fronteira, 1988.

WAISELFISZ, Jacobo. Mapa da Violência Contra os Jovens do Brasil. Rio de Janeiro: Garamond, 1998.

\begin{abstract}
Notas
${ }^{1}$ Art. $^{\circ} 3$ - A criança e o adolescente gozam de todos os direitos fundamentais inerentes à pessoa humana, sem prejuízo da proteção integral de que trata esta Lei, assegurando-se lhes, por lei ou por outros meios, todas as oportunidades e facilidades, a fim de lhes facultar o desenvolvimento físico, mental, moral, espiritual e social, em condições de liberdade e de dignidade (BRASIL, 1990).

2 Refere-se à sigla em inglês de Modular Object Oriented Distance Learning, que consiste num software livre que funciona como uma plataforma virtual que armazena banco de dados, aulas, filmes, criando um Ambiente Virtual de Aprendizagem (AVA) e tem sido muito usado na educação a distância.

${ }^{3}$ A PC 55, que congela gastos públicos por 20 anos, foi aprovada pelo Senado Federal em 13 de dezembro de 2017, mas nasceu na Câmara de Deputados como PEC 247.
\end{abstract}

